\title{
When does Religiosity matter for Attitudes to Immigration? The impact of economic insecurity and religious norms in Europe
}

DOI:

10.1080/14616696.2017.1402122

\section{Document Version}

Accepted author manuscript

Link to publication record in Manchester Research Explorer

Citation for published version (APA):

Storm, I. (2017). When does Religiosity matter for Attitudes to Immigration? The impact of economic insecurity and religious norms in Europe. European Societies. https://doi.org/10.1080/14616696.2017.1402122

\section{Published in:}

European Societies

\section{Citing this paper}

Please note that where the full-text provided on Manchester Research Explorer is the Author Accepted Manuscript or Proof version this may differ from the final Published version. If citing, it is advised that you check and use the publisher's definitive version.

\section{General rights}

Copyright and moral rights for the publications made accessible in the Research Explorer are retained by the authors and/or other copyright owners and it is a condition of accessing publications that users recognise and abide by the legal requirements associated with these rights.

\section{Takedown policy}

If you believe that this document breaches copyright please refer to the University of Manchester's Takedown Procedures [http://man.ac.uk/04Y6Bo] or contact uml.scholarlycommunications@manchester.ac.uk providing relevant details, so we can investigate your claim.

\section{OPEN ACCESS}




\title{
When does Religiosity matter for Attitudes to Immigration? The impact of economic insecurity and religious norms in Europe
}

\author{
Ingrid Storm
}

Cathie Marsh Institute for Social Research, University of Manchester, Manchester, UK

Dr. Ingrid Storm

Cathie Marsh Institute for Social Research

Humanities Bridgeford Street 2.13W

University of Manchester

Oxford Road

Manchester M13 9PL

UK

Telephone: +44 (0)1612750797

E-mail: ingrid.storm@manchester.ac.uk

ORCiD: 0000-0003-4185-9893

Funding details

This work was supported by the British Academy under The Postdoctoral Fellowship Scheme

Biographical note

Ingrid Storm is a British Academy Postdoctoral Fellow at the University of Manchester. She has published extensively on religious change, and on attitudes to immigration and ethnic and religious minorities, in Journal for the Scientific Study of Religion, European Sociological Review and British Journal of Sociology among others. She is currently researching the relationships between economic insecurity and religion in Europe.

Word count: 7578 (including abstract, tables, notes and references, and excluding appendix) 


\section{When does Religiosity matter for Attitudes to Immigration? The impact of economic insecurity and religious norms in Europe}

Religious identity and practice has been associated with attitudes to immigration in Europe, but it is not known how this relationship varies between different cultural and economic contexts. Analysing data from seven waves of the European Social Survey (ESS) 2002-2014 we examine the association cross-nationally and over time, in what was a financially unstable period for many European countries and households. We have two main findings. Firstly, it is not religion per se, but rather conformity to national rates of religiosity which is associated with concern about the economic and cultural consequences of immigration. Secondly, the association between religion and anti-immigration is strengthened in contexts of economic uncertainty. These findings suggest that while religion does not predict immigration attitudes uniformly across countries, when religion reflects cultural conformity, it could become an expression national or ethnic group identity in times of economic insecurity.

Keywords: Religion; immigration attitudes; economic insecurity; unemployment; social norms; Europe

\section{Introduction}

Previous research indicates that religion and immigration attitudes are related, primarily through their mutual relationship with national identities (Storm 2011a). Majority religious identities and behaviours could be a way of signalling belonging to a national community, and distancing oneself from religious and ethnic minorities (Bohman and Hjerm 2014; Demerath 2000; Storm 2011b). The main argument of this paper is that it is not religiosity per se that is related to concerns about immigration, but rather the degree to which religion represents cultural conformity.

Immigration and its economic and cultural consequences have been divisive issues in Europe for most of the 2000s. Opposition to immigration is often attributed to insecurity about the presence of non-national outgroups in the country, whether it be fear that that they represent a threat to security, that cultural differences will lead to conflict or that movements of people will upset the national economy. After the economic downturn in 2007 and 2008, concerns about immigration increased as unemployment levels surged, governments cut back on welfare provisions, and households and businesses struggled to make ends meet. Many governments responded by imposing 
stricter limits on immigration, and the growth of populist anti-immigration political parties across Europe suggests that a large section of the electorate would have preferred even tighter measures. Kinnvall (2004: 757) argues that religion is a particularly likely anchoring point for group interests in times of uncertainty, as it can respond to a need for authority and predictability (Norris and Inglehart 2004: 18) as well as signal in-group identity. However, the relationship between religiosity and attitudes to immigration can seem contradictory, as it varies between countries, and depends on the precise measures used. The primary purpose of this study is to discover under what circumstances religiosity is associated with concerns about immigration.

The relationship between religiosity and concerns about immigration can be expected to strengthen under two conditions. The first condition is that there is coherence between the respondent's national and religious identity, i.e. that the individual's religious affiliation and behaviour conforms to the national norms. The second condition is a situation of insecurity or perceived competition, for example economic hardship or high rates of unemployment. Previous research has shown that economic conditions can interact with ideology (Pardos-Prado 2011) and human values (Davidov and Meuleman 2012) to influence attitudes to immigration, but this study is the first to examine how the relationship between religion and attitudes to immigration varies depending on the national economic context. In the following, we introduce six hypotheses about the relationship between religion and concerns about immigration. Subsequently, data from the first seven waves of the European Social Survey (ESS) 2002-2014 is analysed at the individual level, national level and over time.

\section{Theory}

Opposition to immigration is often attributed to insecurity about the presence of non-national outgroups in the country. Research on what drives public opinion on immigration policy and attitudes to integration of immigrants suggests a very complex mixture of factors. We can divide these into 'Economic concerns' and 'Cultural concerns'. Economic concerns about immigration may be motivated by insecurity about how labour market competition, salary levels and welfare distribution are affected by population growth. Cultural concerns on the other hand could be motivated by fear of change in national or local identity and community, and include references to differences in language, religion, cultural habits as well as race.

However, justifications of political opinions are rarely this clear cut: Economic insecurity may increase in-group identity (Bobo 1983: 1208; Tajfel and Turner 1979), resulting in stronger national pride, racial bias, and fear of out-groups. Sides and Citrin (2007), for example found that 
national pride and a preference for national unity and homogeneity were better predictors of antiimmigration attitudes than any economic measures. Conversely, emotional reactions based on social identities and unconscious racial bias may take on economic post-hoc justifications (Pérez 2010). In sum, a threat to the economy may increase the sense of cultural threat as well, especially for people who already identify strongly with the dominant national culture (Burns and Gimpel 2000).

\subsection{Religion and attitudes to immigration}

There are at least three reasons why religion may be associated with concerns about immigration; religion could be seen as a cultural symbol of the nation, a symbolic boundary for the majority ethnic group, or as an indicator of individual traditional values. Firstly, religion has been associated with nationalism, and in Europe, Christians are more likely to think a Christian affiliation is a prerequisite for belonging to the nation (Kunovich 2006; Storm 2011a). Further, religion has been a prominent topic in debates about immigration and ethnic diversity Europe over the past fifteen years. Muslims constitute a significant proportion of immigrants to Europe (Strabac and Listhaug 2008: 268), and as noted by Sides and Citrin (2007: 501) terrorist acts by Islamist extremists, coupled with the perceived ethnic and religious distinctiveness of Muslim populations, has led to concern about immigration's consequences for national culture. Expression of religious identity, through religious dress and diet has thus become a salient 'symbolic boundary' (Bail 2008: 54), particularly in countries experiencing recent growth in non-western immigration. Thirdly, religiosity has been associated with personality and attitudinal variables related to anti-immigration, such as authoritarianism, conventionalism, ingroup loyalty, and hostility to outgroups (Altemeyer 1981; Jost et al. 2003). Davidov and Meuleman (2012) find that individuals in Europe with high scores on measures of tradition, conformity and security values are more negative to immigration. However, the association between religiosity and anti-immigration depends on the particular measures used. Scheepers et al. (2002) found that while religious affiliation is positively associated with ethnic prejudice in Europe, the more important religion is in people's lives the less prejudiced they are likely to be. This finding is consistent across a number of studies of religion in Europe. Storm (2011a) examined the relationship between religiosity and attitudes to immigration in Western Europe and found that Christian affiliation was generally positively associated with viewing immigration as a threat to national identity. Demerath (2000) argues that 'cultural religion' signals belonging for people who feel that national and local traditions are under threat, even if they do not believe or practice. Religious affiliation in this sense represents nothing more than identification with a majority ethno-national group. In contrast, regular attendance (Storm 2011a) and religious beliefs 
(Scheepers et. al. 2002) are associated with more positive views of immigration. Only a minority of the population in most European countries regularly practice their religion, and these people may be more attuned to the contrast between their own religiosity and the secularity of their country. Religious teachings of altruism and compassion for marginal groups, may also increase support for, or override concerns about immigration among regular attenders (Storm 2011a). We thus expect that religious attendance will be negatively associated with concerns about immigration. As an expression of a symbolic boundary against religious minorities, we hypothesise that only majority affiliation (i.e. major Christian denominations) and not minority religious affiliation is associated with negative attitudes to immigration.

Hypothesis 1) Individual religious service attendance is negatively associated with concerns about immigration.

Hypothesis 2) Religious affiliation with a Christian denomination is positively associated with concerns about immigration.

\subsection{Religious context}

The relationship between religiosity and attitudes to immigration also varies between countries, depending on their particular religious contexts. As Bohman and Hjerm's (2014) research shows, religious people are more tolerant of immigration in countries where the government does not favour one religion. Further, they found that people who identified with the majority religion were more tolerant of immigration in countries with low proportions of majority adherents (Bohman and Hjerm 2014). In other words, religious people were less tolerant the more they conformed to the national religious norms. This supports other research which finds that religious context influences the significance of a particular religious identity and practice. Storm (2011a, 2011b) found that in Britain and Denmark 'nominal' religion, that is religious affiliation without practice, tends to be positively associated with national pride and negative attitudes to immigration. However, the same result was not found in Ireland, the most religious of the countries studied (Storm 2011a). Similarly, Demerath (2000) found that Christian can be used as a label to signify national cultural heritage rather than faith, but the degree of religious practice associated with such 'cultural religion' varied according to national conventions.

This research indicates that it may not be religiosity per se, but rather cultural conformity, which is associated with anti-immigration. The cultural change and cultural difference associated with immigration and immigrants could be experienced as threatening to conservative individuals with a preference for traditions, conformity and the status quo (Davidov and Meuleman 2012). 
Additionally, people who belong to the religious majority are less exposed to, and less familiar with, interaction with people of a different religion, and thus from the perspective of intergroup contact theory, we would expect them to display more concern about the immigration of religious minorities (Pettigrew and Tropp 2008; Schneider 2008). Nominal religiosity is only found to be associated with negative attitudes to immigration and minorities in countries where attendance rates are low (Storm 2011a). In countries where more people actively practice their religion, we may expect that it is religious attendance that is most associated with negative attitudes to immigration.

Hypothesis 3) The higher the rate of the respondent's religious affiliation in the country, the more they will be concerned about immigration

Hypothesis 4) The higher the rate of religious attendance in the country, the more individual religious attendance is associated with concerns about immigration

\subsection{Economic context}

The relationship between religion and concerns about immigration may also be influenced by the economic context. Previous research has found that lower economic development is associated with preferences for ethnic relative to civic national identity (Kunovich 2009), and perceptions of religion as a salient symbolic boundary, and indicator of 'group threat' can be reinforced by economic insecurity (Bail 2008: 54). Immerzeel and van Tubergen (2011) and Storm (2017) also find robust associations between religion and financial insecurity at both the individual and country level in Europe. Religion could appeal to economically insecure individuals by providing a coherent group identity and social and emotional support (Bradshaw and Ellison 2010; Storm 2017). As a repository for security, religiosity can take on a meaning of nationalism, ethnocentrism and other forms of ingroup identity in situations of external threat (Kinnvall 2004). We thus expect the relationship between religiosity and attitudes to immigration to be stronger in countries and times with less economic growth and higher unemployment rates.

Hypothesis 5) The higher the level of unemployment in the country, the more individual religiosity is associated with concerns about immigration

Hypothesis 6) The wealthier the country, the less individual religiosity is associated with concerns about immigration 


\section{Data and method}

The data used for the analysis comes from the first seven waves of the European Social Survey (ESS 2017), collected every two years over ten years from 2002 to 2014. This dataset covers more than 15000 individuals in 32 countries $^{1}$. In addition to the integrated files, available from http://www.europeansocialsurvey.org/data/, we imported two country-level variables from Eurostat (2016): per cent unemployed and GDP. Table 1 shows the countries and their values on key variables. To maximise the sample size, all countries with data on the dependent variables were included in the analysis. ${ }^{2}$. Details of all variables can be found in the appendix.

To account for the fact that the individuals in the sample are clustered within countries and survey waves, we employ a hierarchical linear model with individuals nested within countries within years. The first models include the predictors of attitudes to immigration at the individual level including frequency of religious service attendance (Table 2). Secondly, using the same modelling technique, we examine the predictors at the country level, including macro-economic measures such as GDP per capita and unemployment rates, as well as cross-level interactions between individuallevel and country-level variables (Table 3 and 4).

\subsection{Dependent variable}

There are two dependent variables measuring attitudes to immigration based on economic concerns and cultural concerns respectively. Both questions were asked in all seven waves of the survey and measured on an 11-point scale. They have been recoded so that higher values indicate a more negative view of immigration:

Economic concern: 'Would you say it is generally bad or good for [country]'s economy that people come to live here from other countries?' [0) Good - 10) Bad]

Cultural concern: 'Would you say that [country]'s cultural life is generally undermined or enriched by people coming to live here from other countries?' [0) Enrich-10) Undermine]

There is a relatively high correlation between the two variables $(\mathrm{r}=0.625, \mathrm{P}=0.000)$. However, by examining these variables separately, we can measure which is more related to economic and religious variables respectively. Another advantage is that economic and cultural justifications do not have to be included as controls in the models, as they are already implied in the questions. Country means for both variables can be seen in Table 1 . 


\subsection{Independent variables}

The religious variables are the main variables of interest. The individual religiosity variables in the models include affiliation and attendance. Firstly, there are seven categories of religious denominational affiliation with no religious affiliation as the reference category ${ }^{3}$. Secondly, "Proportion same religion", is the proportion of the sample from the same country and survey year as the respondent who shares the respondent's (non-)religious affiliation. This measure indicates to what extent the respondent's answer to the question about religious affiliation is typical for their country at the time of the survey, and can be used whether or not they belong to a religion.

Religious service attendance is used as a measure of religious practice because it to a greater extent than private prayer and belief indicates a level of interaction with a religious community ${ }^{4}$. It is measured by a five category variable of frequency of attendance from never to more than once a week. $^{5}$

At the country-year level the proportion who attend religious services at least monthly is used as a measure of the religious context ${ }^{6}$. At the country-year level we also include two macroeconomic variables. $\log$ GDP is the $\log$ of the Gross Domestic Product (per capita in PPS (Purchasing Power Standard against the Euro) and Unemployment rate is defined as the annual average percentage of the labour force that is unemployed and actively seeking work (Eurostat 2016). These are correlated $(\mathrm{r}=-0.444, \mathrm{P}<0.001)$, and are entered in separate models to avoid multicollinearity.

Because one of the dependent variables is economic concern about immigration, it is important to control for economic variables at the individual level. We include eight categories of economic activity, including unemployment, and the respondent's self- assessment of how difficult it is to get by on their household income (4 categories).

A number of other variables are included as controls because they have been shown to relate to the outcome variables as well as the variables of interest. Age ${ }^{7}$, gender and level of education, are strongly associated with immigration attitudes (Hainmueller and Hiscox 2007; Strabac and Listhaug 2008: 271) as well as religiosity and financial security. Personal immigration history could also be related to immigration concerns as well as their religiosity and socio-economic position (Kogan 2006). For further details on the variables, see the Appendix.

\section{Results}

\subsection{Descriptive analysis}

Table 1 shows the mean values for six variables of interest for the 31 countries in the sample. Cyprus, Greece and Turkey have particularly high mean values on both dependent variables, whereas 
Iceland, Luxembourg and Switzerland score lower than average ${ }^{8}$. The table also illustrates the difference between levels of religious attendance, and levels of religious affiliation. There are countries that have high rates of both (e.g. Poland) and low rates of both (e.g. Estonia), but also those that have high levels of religious affiliation, but low rates of attendance (e.g. Denmark).

\section{[TABLE 1 here]}

The table also includes the Pearson's correlations between religious attendance and each dependent variable in each country. The overall correlation for the whole sample is 0.01 for economic concerns and 0.04 for cultural concerns but these vary between countries, and because much of the variation is around the mid-point of the scale - the percentage of people at each rate of attendance who express negative views of immigration vary considerably depending on the country. For an illustration of this see Figure 1, which shows the relationship in four countries. Although there is no clear pattern, and the levels of concerns vary a great deal, Catholic and Orthodox countries with higher levels of religious attendance (such as Poland and Greece) generally have more positive relationship between religious attendance and concerns about immigration than more secular and protestant countries like Great Britain and Sweden.

\section{[FIGURE 1 here]}

It should be noted that these variables also vary over time. Economic concerns about immigration peaked in 2004, with another increase from 2008 to 2010. 2008-2010 was the period of economic recession in Europe, seen most clearly in the increase in unemployment levels from 6.6 to 9.4 per cent. 2010 was also the only year where log GDP did not increase from the previous year. Religiosity has had a slow and relatively steady decline over the period.

\subsection{Individual level results}

The individual level analysis is shown in Table 2. Model 1 controls for sociodemographic and economic variables, as well as religious denomination and model 2 includes proportion same religion and religious attendance. Economic concerns about immigration are overwhelmingly accounted for by individual-level variation ( 84 per cent). Seven per cent of the variation is by country, and nine per cent by country-year. Cultural concerns are more context dependent: 72 percent of the variance is at the individual level and 14 percent at country and country-year level respectively ${ }^{9}$. 
Religious service attendance is negatively associated with economic concerns about immigration, supporting Hypothesis 1. It is not significantly associated with cultural concerns about immigration. This may reflect that church attendance, while a predictor of some tolerant attitudes to immigration, is also considered a national cultural symbol 'under threat'. When asked directly about the cultural consequences for the nation, religious attenders are more sceptical of the benefits of immigration, than when asked about the economy.

Compared to the nonreligious, Catholics and Protestants are more likely to express concerns about immigration, whereas Muslims and other non-Christians are more likely to see immigration as beneficial to the country. This supports Hypothesis 2. In the second model we see that the coefficient for the proportion with the same religious affiliation is positive, which means that respondents who belong to dominant denominational affiliations, whether those are Orthodox, Catholic, Protestant, Muslim, or no religious affiliation, are more likely to express concern about immigration than those who are religious minorities in their country. This result, illustrated in Figure 2, supports Hypothesis 3.

[FIGURE 2 here]

Once controlling for attendance and proportion with the same religion, the positive coefficients for Catholics and Protestants increase, offering further support for Hypothesis 2. In other words, on top of being a majority affiliation, associated with increased concerns about immigration, Protestants and Catholics are more likely to be concerned about immigration than non-affiliates. The reason for this could be that regardless of the proportion of nonreligious people in the population, belonging to an established or traditionally dominant religion is considered more culturally conformist than non-religiosity (Storm 2011a). Conversely, the negative coefficients for nonChristian religion are reduced in Model 2, meaning that Non-Christians' positive attitudes to immigration are in part due to their status as religious minorities. In addition, non-Christian religious people are more culturally different to the majority than non-religious "minorities" who in most situations would be considered part of the dominant culture. While specific denominational affiliation is associated with both economic and cultural concerns, the effect is more pronounced for cultural concerns, which supports the assumption that affiliation with a dominant religion can reflect a sense of national cultural belonging.

Other strong predictors of attitudes to immigration are education and a personal history of migration, which have similarly negative associations with the outcome variables. Socio-economic 
variables are also good predictors of concerns about immigration at the individual level. Although they are particularly associated with economic concerns about immigration, people who are employed and satisfied with their household income are more likely to have a positive view of both the economic and cultural consequences of immigration.

\section{[TABLE 2 here]}

\subsection{Country level results}

In Table 3 (Economic concerns) and Table 4 (Cultural concerns) the results are shown for the same model (model 2) with country-year level variables included one by one in model 3, 7 and 7. In model 4,6 , and 8 we introduce interaction effects between religious service attendance and the contextual variables to test Hypothesis 4, 5 and $6 .{ }^{10}$ All the individual level variables from Table 2 are included, but for simplicity, only the main variables of interest are shown. The other individual level coefficients, including religious denomination, changed very little with the introduction of countryyear level variables and interactions.

As model 3 shows, the national rate of religious attendance does not predict either economic or cultural concerns about immigration on its own. When the interaction effect is introduced in model 4 however, we see that the association between individual religiosity and attitudes to immigration varies between countries, depending on their rate of religiosity. Within countries with higher levels of religious attendance, people attending religious services more often are more likely than non-attenders to be negative to immigration. Supporting Hypothesis 4, this indicates that the more religious the country, the more individual religiosity is associated with concerns about immigration. As with religious affiliation (H3), the implication of an individual's religious practice depends on how prevalent it is in the country, and the interaction is strong and significant for both economic and cultural immigration concerns. As shown in Figure 3, while overall, regular religious participation is associated with thinking immigration is good, rather than bad, for the country's economy, this effect is reduced, and even reversed, in countries where more than $60 \%$ of the population attend at least once a month,

Model 5 shows that national unemployment rates are positively associated with thinking immigration is bad for the economy, but not with cultural concerns about immigration. Similarly, in model 7 it can be observed that people in countries with higher GDP have more positive attitudes to the economic benefits of immigration than people in poorer countries, whereas there is no direct 
relationship between GDP and cultural concerns about immigration. In short, people are more worried about the economic consequences of immigration in more economically insecure contexts.

As models 6 and 8 show, however, individual religious practice is more associated with both economic and cultural concerns about immigration in contexts of lower GDP and lower unemployment, supporting Hypothesis 5 and 6. The relationship is illustrated in Figure 3, which shows the predicted values of thinking immigration is bad for the economy by unemployment levels, for people who attend religious services at least monthly and less often respectively, and controlling for all variables included in Table 2. Among regular church attenders, there is about one point difference on the seven point scale of thinking immigration is bad for the economy, between low and high unemployment countries, whereas there is less difference among non-attenders. We also find that while regular religious service attendance was generally negatively associated with thinking immigration is bad for the economy, it seems to have the opposite association in countries with high unemployment, low GDP and high levels of religiosity ${ }^{11}$.

Models 4 and 6 have the best fit of any of the models ${ }^{12}$, which suggests that both the higher religiosity levels as well as the higher economic uncertainty of poorer countries may provide the best explanation for why there is relationship between religious practice and negative attitudes to immigration in these countries. Religiously observant people in more religious countries and nonreligious people in less religious countries are most pessimistic about the consequences of immigration. This is to be expected from a social identity perspective, as anti-immigration is generally associated with both adherence to social conventions (Altemeyer 1981) and national identification (Storm 2011a; Bohman and Hjerm 2014). At the same time, religion as symbolic boundary is especially salient in more difficult economic contexts, which is consistent with a positive relationship between material insecurity and religious identity (Norris and Inglehart 2004; Immerzel and van Tubergen 2011; Storm 2017).

[TABLE 3 and 4 here]

[FIGURE 3 here]

\section{Discussion}

The aim of this research was to analyse how the association between religiosity and attitudes to immigration varies between different religious and economic contexts. Religiosity appears to have differential relationship to immigration attitudes depending both on the measures used and the national context. Religious identification with dominant or majority denominations (including no 
religion) was positively associated with concerns about immigration, whereas minority affiliation and religious service attendance was associated with more positive attitudes to immigration. These findings support Hypothesis 1 and 2, and corroborate the earlier literature on majority religious identity and practice as potential expressions of a symbolic boundary (Bail 2008; Kunovich 2006) which defines national identity against a cultural outgroup. While it was not possible to test the mechanism of the association across all seven waves of data, supplementary analysis of the 2014 wave of data (Table S1) indicates the relationships between religiosity and immigration concerns can be accounted for by a religiously based national identity and a specific opposition to the immigration of religious minorities.

We also find that the context of the country moderates the relationship between religiosity and attitudes to immigration. Religious service attendance is only associated with pro-immigration attitudes in countries with low religious attendance rates. In countries with high attendance rates religious practice is associated with negative attitudes to immigration, supporting Hypothesis 3. Similarly, affiliation with a religious denomination is only associated with negative attitudes to immigration in countries with high rates of affiliation with that same religion. Conversely, the more nonreligion and minority religion is at odds with majority religious culture, the more likely nonreligious and minority religious people are to think immigration enriches national culture. This indicates that the relationship between religiosity and anti-immigration is a reflection of religion as an expression of national cultural identity (Bohman and Hjerm 2014; Demerath 2000; Storm 2011b), and values of conservatism or conformity (Davidov and Meuleman 2012). The association between religion and immigration attitudes is there, but only insofar as the religiosity reflects the dominant social norms within the national context. As Bohman and Hjerm (2014: 950) put it, 'being more included makes the religious more likely to exclude'.

The relationship between religious service attendance and immigration attitudes, also depends on the economic context. In support of Hypothesis 5 and 6 we found that the higher the country's GDP and employment levels, the less religious practice is associated with negative attitudes to immigration. Economic hardship, whether measured as unemployment, difficulty getting by on one's household income, or macroeconomic measures such as low GDP or high unemployment levels, consistently predicts negative attitudes about immigration's effect on the economy. This was robust whether measured within countries, between countries, or over time, and supports the prediction of both intergroup conflict theory and social identity theory, that attitudes to outgroups would become more negative in the face of uncertainty and threat (Tajfel and Turner 1979). The finding that the economic context also moderates the association between religiosity and 
immigration attitudes, suggests a close relationship between material insecurity and concern about the protection of cultural and religious national identity (Norris and Ingelhart 2004).

An important limitation is that some of the findings could be due to unobserved differences between the 32 countries (te Grotenhuis et al. 2015). To uncover the details of the individual level mechanisms and the relative importance of individual-level and contextual variables, analysis of panel data is needed. Another limitation of this data is that it does not allow us to consider the role of religious belief. For example, it is highly plausible that religious beliefs, norms and values transmitted in religious services, rather than service attendance per se, account for some of the relationship observed between religious attendance and positive attitudes to immigration. Further research in this area is needed to understand what elements of religious service attendance (ritual, beliefs, social networks etc.) contribute to the increased or decreased support for immigration in different contexts.

\section{Conclusion}

This research show that religious identity and practice are associated with concerns about immigration in Europe, but that the effect of religion varies depending on both the religious and economic context. There are two main findings.

Firstly, conformity to national rates of religious practice is associated with concern about the economic consequences and cultural influence of immigration. Religious people in religious countries are more worried about immigration, but so are nonreligious people in nonreligious countries. This suggests that it is not religious beliefs or practices per se that are associated with antiimmigration, but religion as an expression of national belonging, conformity to social norm or conservative values.

Secondly, the association between religious identity and anti-immigration attitudes is exacerbated in times of economic uncertainty and threat. The positive association between religious service attendance and negative attitudes to immigration is stronger in contexts of high unemployment and low economic growth, and this effect can be seen both between countries and within countries over time. This finding indicates that the symbolic meaning of religious practice could change in times of national economic insecurity, to become more associated with expressions of national or ethnic group identity. 


\section{Notes}

${ }^{1}$ Information about sampling and survey response rates for each country and survey year is available in the Survey Documentation Reports and Fieldwork Summaries http://www.europeansocialsurvey.org/data/round-index.html

${ }^{2}$ Turkey is the only Muslim majority country. Excluding it does not substantially affect the results.

${ }^{3}$ The other 6 categories are Catholic, Protestant, Orthodox, Other Christian, Muslim and Other non-Christian. The original variable had separate categories for "Jewish", "Eastern" and "Other non-Christian" religions, but these were combined as each amounted to less than $0.4 \%$ of the sample.

${ }^{4}$ A previous model included weekly prayer, but this variable was mostly insignificant and excluded from the final analysis to avoid multicollinearity. There is no measure of religious belief available in the dataset.

${ }^{5}$ While there is an additional category of "Once a day" in the original variable, less than one percent of the sample (and less than ten respondents in some countries) reported this level of attendance frequency, and it was recoded as "More than once a week" to increase comparability across countries and denominations. Recoding frequency of religious practice as a dichotomous variable of once a month or less often, makes no significant difference to the model fit.

${ }^{6}$ The country's major denomination was not included as a contextual variable due to high correlations with individual denominational affiliation (Cramer's $\mathrm{V}=0.68$ ). In an alternative model a variable of whether the respondent belonged to the dominant country denomination or a minority religion, was included instead of proportion of adherents to the same religion. The results were largely similar, with "majority" affiliates being consistently more concerned, and "minority" affiliates less concerned about immigration compared to non-affiliates. In order to test the "conformity" hypothesis for affiliates and non-affiliates with the same measure, proportion of adherents to the same religion was included in the final model. Results of the alternative models are available from authors on request.

${ }^{7}$ Age is multiplied by 100 to make the tables easier to read

${ }^{8}$ The economic variables are not available for Russia and Ukraine

${ }^{9}$ The models in Table 2, 3 and 4 are not directly comparable, since the sample size varies depending on which variables are included. Log likelihood tests have been performed by comparing the model with the less complex model conducted on the same sample, i.e. model 7 is compared to model 2 without the cases missing values on GDP.

${ }^{10}$ Other country level variables that have been controlled for in alternative models are per cent foreign citizens, per cent foreign-born populations, the Gini coefficient, and the Human development Index, but neither of them were significant, and they were thus excluded from the analysis.

${ }^{11}$ In an additional analysis of changes over time (fixed effects model of country-level variables), we found that increases in unemployment were associated with increased economic concerns about immigration, but only in religious countries. The results are available on request

${ }^{12}$ It is difficult to separate the effects of economic and religious contextual variables as they are correlated. However, including the interactions simultaneously for model 4 and model 6, confirms that the interaction with national rates of religiosity accounts for most, but not all of the variance. The interaction with unemployment levels was significant but small for both outcome variables. These models are not included here due to collinearity. 


\section{References}

Altemeyer, B. (1981) Right-Wing Authoritarianism, Winnipeg: University of Manitoba Press.

Bail, C. A. (2008) 'The Configuration of Symbolic Boundaries against Immigrants in Europe', American Sociological Review 73 (1): 37-59.

Bobo, L. (1983) 'Whites' Opposition to Busing: Symbolic Racism or Realistic Group Conflict?', Journal of Personality and Social Psychology 45 (6): 1196-1210.

Bohman, A. and Hjerm, M. (2013) 'How the Religious Context Affects the Relationship between Religiosity and Attitudes towards Immigration', Ethnic and Racial Studies 37 (6): 937-57.

Bradshaw, M. and Ellison, C. G. (2010) 'Financial Hardship and Psychological Distress: Exploring the Buffering Effects of Religion', Social Science \& Medicine 71 (1): 196204.

Burns, P. and Gimpel, J. G. (2000) 'Economic Insecurity, Prejudicial Stereotypes, and Public Opinion on Immigration Policy', Political Science Quarterly 115 (2): 201-225.

Davidov, E. and Meuleman, B. (2012) 'Explaining Attitudes Towards Immigration Policies in European Countries: The Role of Human Values', Journal of Ethnic and Migration Studies 38 (5): 757-75.

Demerath, N. J. (2000) 'The Rise of 'Cultural Religion' in European Christianity: Learning from Poland, Northern Ireland, and Sweden', Social Compass 47 (1): 127-39.

ESS (European Social Survey) (2017). European Social Survey Cumulative File Wave 1-7. http://www.europeansocialsurvey.org.

Eurostat. (2016) Database. http://ec.europa.eu/eurostat/data/database.

Hainmueller, J. and Hiscox, M. J. (2007), 'Educated Preferences: Explaining Attitudes Toward Immigration in Europe', International Organization 61 (2): 399-442.

Immerzeel, T. and van Tubergen F. (2011), 'Religion as Reassurance? Testing the Insecurity Theory in 26 European Countries', European Sociological Review 29 (2): 359-72.

Jost, J.T., Glaser, J.A., Kruglanski W. and Sulloway, F. J. (2003) 'Political Conservatism as Motivated Social Cognition', Psychological Bulletin 129 (3): 339-75.

Kinnvall, C. (2004) 'Globalization and Religious Nationalism: Self, Identity and the Search for Ontological Security’, Political Psychology 25 (5): 741-67.

Kogan, I. (2006) 'Labor Markets and Economic Incorporation among Recent Immigrants in Europe’, Social Forces 85 (2): 697-721. 
Kunovich, R. M. (2006) 'An Exploration of the Salience of Christianity for National Identity’, Sociological Perspectives 49 (4): 435-60.

Kunovich, R. M. (2009) 'The Sources and Consequences of National Identification', American Sociological Review 74 (4): 573-93.

Norris, P. and Inglehart, R. (2004) Sacred and Secular: Religion and Politics Worldwide, Cambridge: Cambridge University Press.

Pérez, E. O. (2010) 'Explicit Evidence on the Import of Implicit Attitudes: The IAT and Immigration Policy Judgments', Political Behavior 32 (4): 517-45.

Pettigrew, T.F. and Tropp, L.R. (2006) 'A meta-analytic test of intergroup contact theory', Journal of Personality and Social Psychology 90 (5): 751-783.

Pardos-Prado, S. (2011) 'Framing Attitudes Towards Immigrants in Europe: When Competition Does Not Matter', Journal of Ethnic and Migration Studies 37 (7): 999 1015.

Scheepers, P., Gijsberts M. and Hello, E. (2002) 'Religiosity and Prejudice against Ethnic Minorities in Europe: Cross-National Tests on a Controversial Relationship', Review of Religious Research 43 (3): 242-65.

Schneider, S. L. (2008) “Anti-Immigrant Attitudes in Europe: Outgroup Size and Perceived Ethnic Threat”, European Sociological Review 24 (1): 53-67.

Sides, J. and Citrin, J. (2007) 'European Opinion About Immigration: The Role of Identities, Interests and Information’, British Journal of Political Science 37 (3): 477-504.

Storm, I. (2011a) "'Christian Nations"? Ethnic Christianity And Anti-Immigration Attitudes In Four Western European Countries', Nordic Journal of Religion and Society 24: 7596.

Storm, I. (2011b) 'Ethnic Nominalism and Civic Religiosity: Christianity and National Identity in Britain', The Sociological Review 59 (4): 828-46.

Storm, I. (2017) 'Does Economic Insecurity Predict Religiosity? Evidence from the European Social Survey 2002-2014', Sociology of Religion 78 (2): 146-172.

Strabac, Z. and Listhaug, O. (2008) 'Anti-Muslim Prejudice in Europe: A Multilevel Analysis of Survey-Data from 30 Countries', Social Science Research 37 (1): 268-86.

Tajfel, H, and Turner, J. (1979) 'An Integrative Theory of Intergroup Conflict', in W.G. Austin and S. Worchel (eds.), The Social Psychology of Intergroup Relations, Monterey, CA: Brooks-Cole, pp. 33-47.

Te Grotenhuis, M., Scholte, M., de Graaf, N. D. and Pelzer, B. (2015) 'The between and within Effects of Social Security on Church Attendance in Europe 1980-1998: The Danger of Testing Hypotheses Cross-Nationally', European Sociological Review 31 (5): 643-54. 
Table 1: Mean values and percentages of variables of interest by country

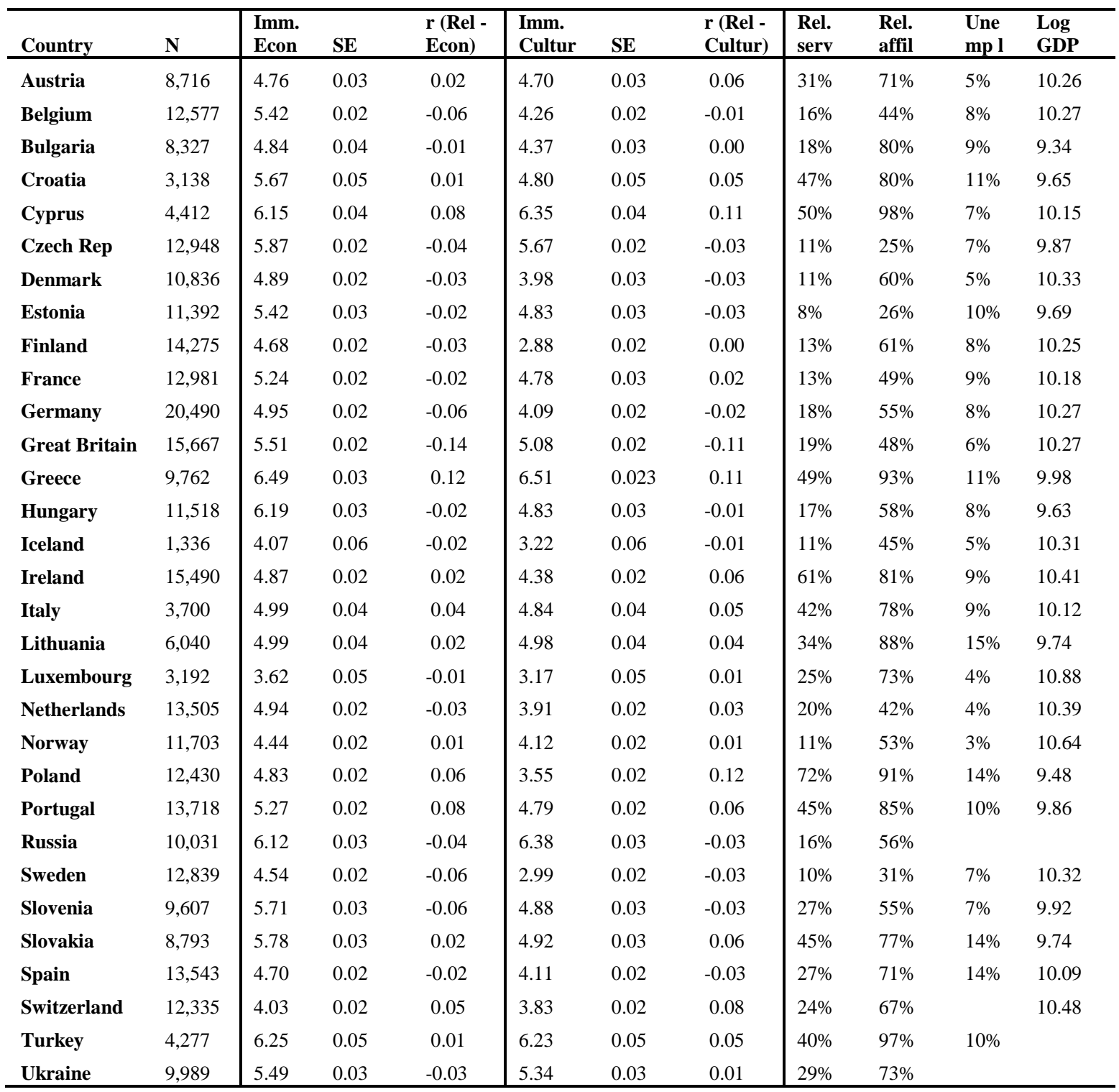

ESS 2002-2014, Imm. Econ= Mean 'Immigration bad for economy', Imm.Cultur= Mean 'Immigration undermines the country's cultural life'; $\mathrm{SE}=$ Standard error; $r=$ Pearson's $r$ correlation between religious service attendance and immigration concerns; Rel serv=Percentage attend religious services at least once a month; Rel affil: Percentage belong to a religion; Unempl: Percent unemployed; Log GDP 
Table 2: Multilevel model: Individual level analysis

\begin{tabular}{|c|c|c|c|c|c|c|c|c|}
\hline \multirow[b]{3}{*}{ Individual level variables } & \multicolumn{4}{|c|}{ "Immigration bad for economy" } & \multicolumn{4}{|c|}{ "Immigration undermines cultural life" } \\
\hline & 1 & & 2 & & 1 & & 2 & \\
\hline & Coef. & S.E. & Coef. & S.E. & Coef. & S.E. & Coef. & S.E. \\
\hline Age*100 & 0.014 & 0.008 & $0.016+$ & 0.008 & $0.030 * *$ & 0.008 & $0.032 * *$ & 0.008 \\
\hline Female & $0.208 * *$ & 0.009 & $0.214 * *$ & 0.009 & $-0.102 * *$ & 0.009 & $-0.103 * *$ & 0.009 \\
\hline \multicolumn{9}{|c|}{ Education (ref: No qualification) } \\
\hline Lower secondary & $-0.154 * *$ & 0.017 & $-0.154 * *$ & 0.017 & $-0.176^{* *}$ & 0.017 & $-0.169 * *$ & 0.017 \\
\hline Upper secondary & $-0.443 * *$ & 0.016 & $-0.446 * *$ & 0.016 & $-0.517 * *$ & 0.016 & $-0.512 * *$ & 0.016 \\
\hline Post-secondary & $-0.693 * *$ & 0.025 & $-0.696 * *$ & 0.025 & $-0.808 * *$ & 0.025 & $-0.802 * *$ & 0.025 \\
\hline Tertiary & $-1.205 * *$ & 0.017 & $-1.208 * *$ & 0.017 & $-1.275^{* *}$ & 0.017 & $-1.271 * *$ & 0.017 \\
\hline \multicolumn{9}{|c|}{ Immigration history (Ref: no) } \\
\hline One parent & $-0.203 * *$ & 0.020 & $-0.200 * *$ & 0.020 & $-0.274 * *$ & 0.020 & $-0.272 * *$ & 0.020 \\
\hline Both parents & $-0.374 * *$ & 0.031 & $-0.349 * *$ & 0.031 & $-0.494 * *$ & 0.031 & $-0.475^{* *}$ & 0.031 \\
\hline Born abroad & $-0.803 * *$ & 0.016 & $-0.778 * *$ & 0.017 & $-0.753 * *$ & 0.017 & $-0.728 * *$ & 0.017 \\
\hline \multicolumn{9}{|c|}{ Employment (ref: Employed long term) } \\
\hline Limited contract & 0.003 & 0.017 & 0.004 & 0.017 & $-0.052 *$ & 0.017 & $-0.052 *$ & 0.017 \\
\hline Self-employed & $-0.048 *$ & 0.015 & $-0.043 *$ & 0.015 & $0.047 *$ & 0.016 & $0.047 *$ & 0.016 \\
\hline In education & $-0.507 * *$ & 0.017 & $-0.506^{* *}$ & 0.017 & $-0.486^{* *}$ & 0.017 & $-0.483^{* *}$ & 0.017 \\
\hline Unemployed & $0.130 * *$ & 0.020 & $0.133 * *$ & 0.021 & $0.077 * *$ & 0.021 & $0.077 * *$ & 0.021 \\
\hline Retired / Disability & $0.119 * *$ & 0.012 & $0.130 * *$ & 0.012 & $0.254 * *$ & 0.012 & $0.257 * *$ & 0.012 \\
\hline Housework & $0.059^{*}$ & 0.017 & $0.065 * *$ & 0.017 & $0.109 * *$ & 0.017 & $0.108^{* *}$ & 0.017 \\
\hline Military / Other & -0.050 & 0.041 & -0.045 & 0.041 & -0.045 & 0.041 & -0.046 & 0.041 \\
\hline \multicolumn{9}{|c|}{ Feelings about household income (ref: Living Comfortably) } \\
\hline Coping & $0.332 * *$ & 0.011 & $0.331 * *$ & 0.011 & $0.253 * *$ & 0.011 & $0.253 * *$ & 0.011 \\
\hline Difficult & $0.611 * *$ & 0.014 & $0.609 * *$ & 0.014 & $0.457 * *$ & 0.015 & $0.457 * *$ & 0.015 \\
\hline Very difficult & $0.913 * *$ & 0.020 & $0.914 * *$ & 0.020 & $0.636 * *$ & 0.020 & $0.639 * *$ & 0.020 \\
\hline \multicolumn{9}{|c|}{ Religious denomination (ref: None) } \\
\hline Roman Catholic & $0.071 * *$ & 0.012 & $0.106^{* *}$ & 0.014 & $0.229 * *$ & 0.013 & $0.214 * *$ & 0.014 \\
\hline Protestant & -0.015 & 0.015 & $0.057 * *$ & 0.016 & $0.120 * *$ & 0.015 & $0.153 * *$ & 0.016 \\
\hline Eastern Orthodox & -0.028 & 0.024 & -0.015 & 0.024 & $0.055+$ & 0.024 & 0.042 & 0.025 \\
\hline Other Christian & $-0.188 * *$ & 0.038 & 0.012 & 0.040 & $-0.185^{* *}$ & 0.038 & -0.071 & 0.041 \\
\hline Muslim & $-0.633 * *$ & 0.035 & $-0.484 * *$ & 0.037 & $-0.731 * *$ & 0.036 & $-0.639 * *$ & 0.038 \\
\hline Other non-Christian & $-0.448 * *$ & 0.053 & $-0.286 * *$ & 0.054 & $-0.500 * *$ & 0.053 & $-0.375^{* *}$ & 0.055 \\
\hline Religious service attenda & & & $-0.051 * *$ & 0.005 & & & -0.004 & 0.005 \\
\hline Proportion same religion & & & $0.262 * *$ & 0.026 & & & $0.252 * *$ & 0.026 \\
\hline Constant & $5.363 * *$ & 0.111 & $5.292 * *$ & 0.111 & $4.980 * *$ & 0.168 & $4.838 * *$ & 0.166 \\
\hline \multicolumn{9}{|l|}{ Random-effects } \\
\hline Country & $0.594 * *$ & 0.081 & $0.583 * *$ & 0.080 & $0.921 * *$ & 0.119 & $0.906^{* *}$ & 0.117 \\
\hline (Country) Year & $0.285^{* *}$ & 0.018 & $0.285^{* *}$ & 0.018 & $0.219 * *$ & 0.015 & $0.219 * *$ & 0.015 \\
\hline Individual & $2.269 * *$ & 0.003 & $2.267 * *$ & 0.003 & $2.297 * *$ & 0.003 & $2.296^{* *} *$ & 0.003 \\
\hline $\mathbf{N}$ individual & 284,075 & & 282,733 & & 285,131 & & 283,801 & \\
\hline $\mathbf{N}$ (country) year & 160 & & 160 & & 160 & & 160 & \\
\hline N country & 31 & & 31 & & 31 & & 31 & \\
\hline Log likelihood & -636161.9 & & -632929.1 & & -642023.8 & & -638841.1 & \\
\hline LR chi & & & 216.4 & & & & 95.83 & \\
\hline $\mathbf{P}$ & & & 0.000 & & & & 0.000 & \\
\hline
\end{tabular}

ESS 2002-2014; ${ }^{*} * \mathrm{P} \leq 0.001,{ }^{*} \mathrm{P} \leq 0.01,+\mathrm{P} \leq 0.05$ 
Table 3: Multilevel model with contextual variables: "Immigration bad for the economy"

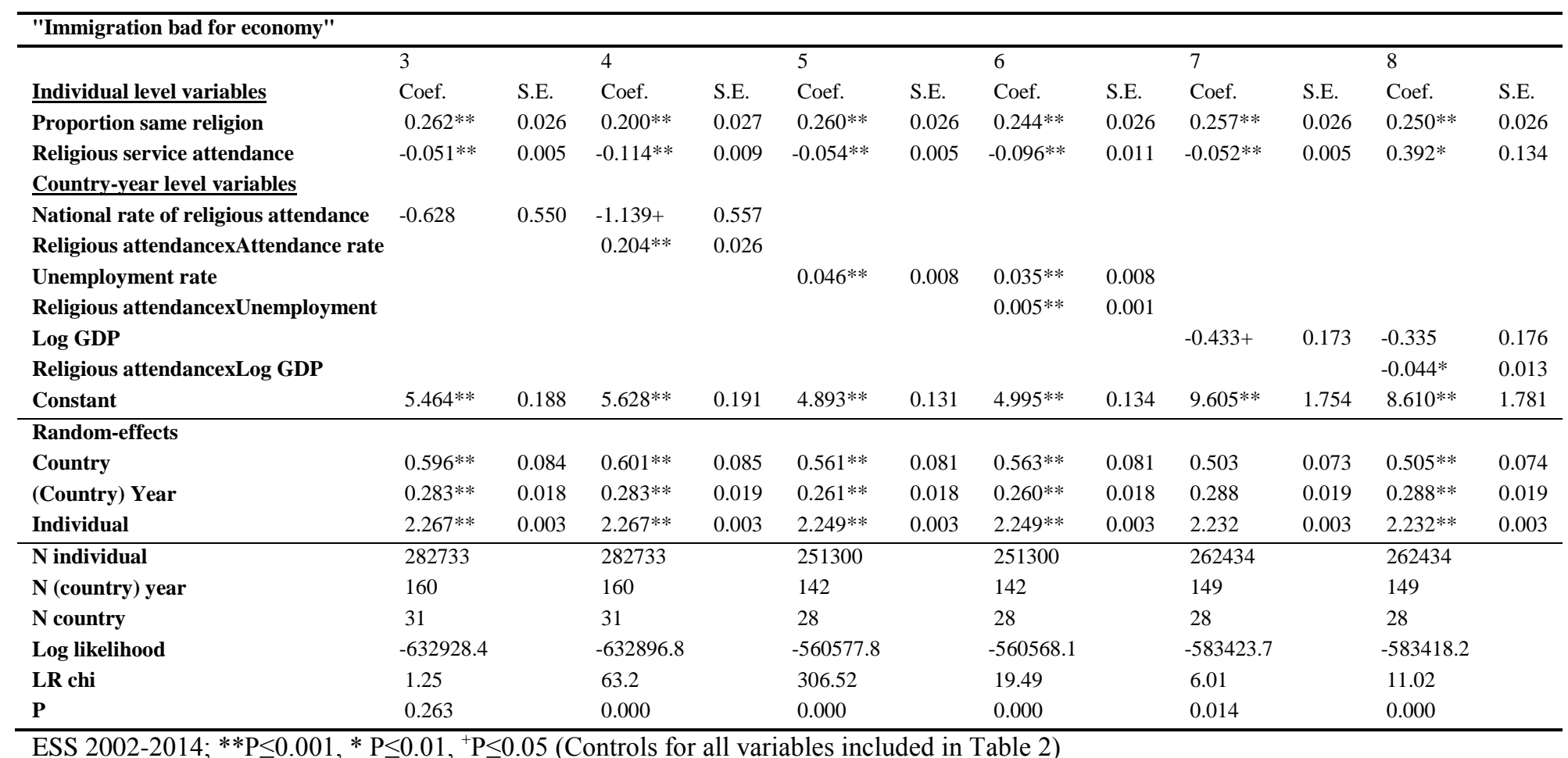

ESS 2002-2014; ${ }^{* *} \mathrm{P} \leq 0.001,{ }^{*} \mathrm{P} \leq 0.01,{ }^{+} \mathrm{P} \leq 0.05$ (Controls for all variables included in Table 2 ) 
Table 4: Multilevel model with contextual variables: "Immigration undermines cultural life"

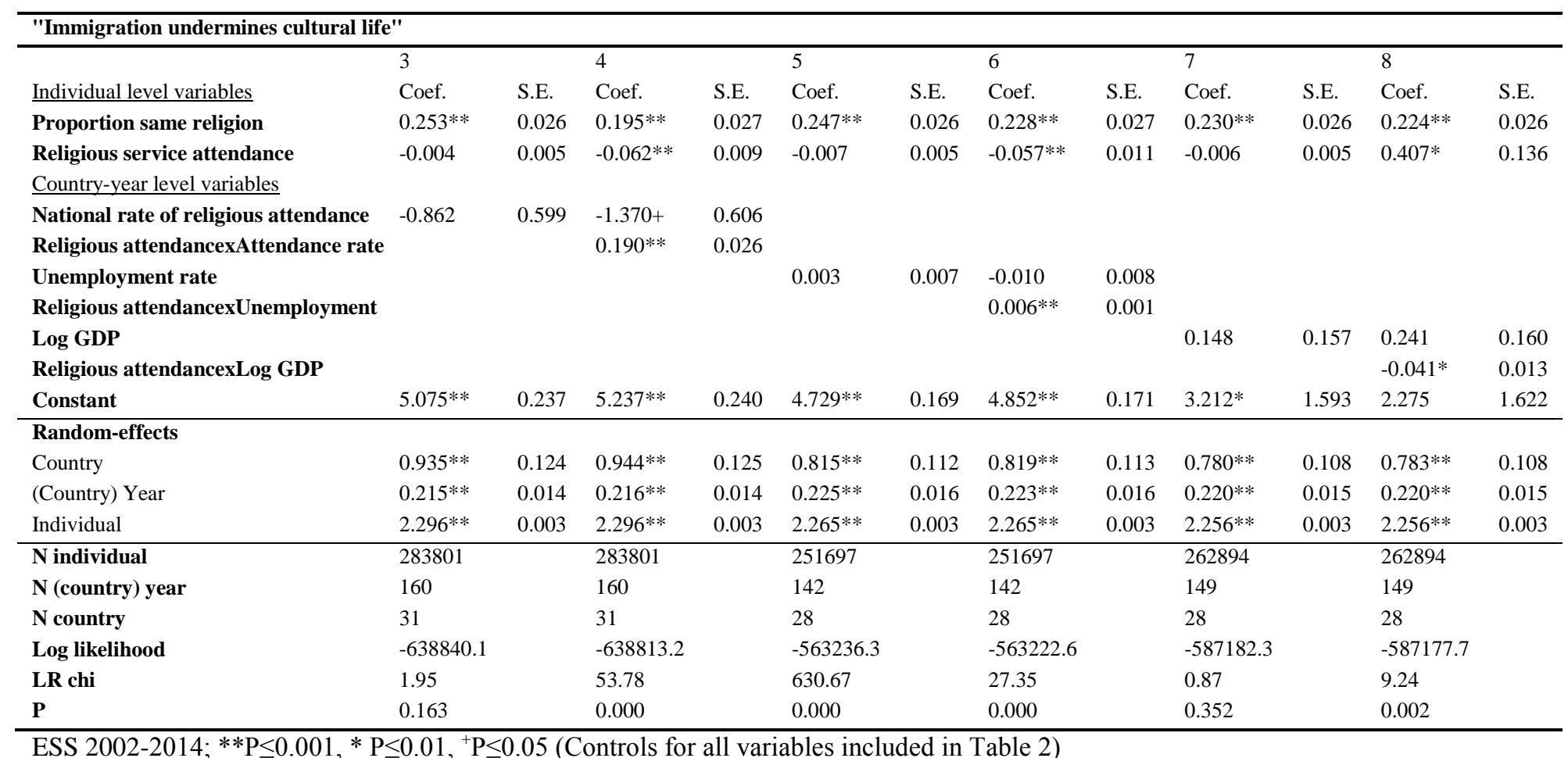

ESS 2002-2014; ${ }^{* *} \mathrm{P} \leq 0.001,{ }^{*} \mathrm{P} \leq 0.01,{ }^{+} \mathrm{P} \leq 0.05$ (Controls for all variables included in Table 2 ) 
Figure 1: Immigration concerns by religious service attendance in four countries

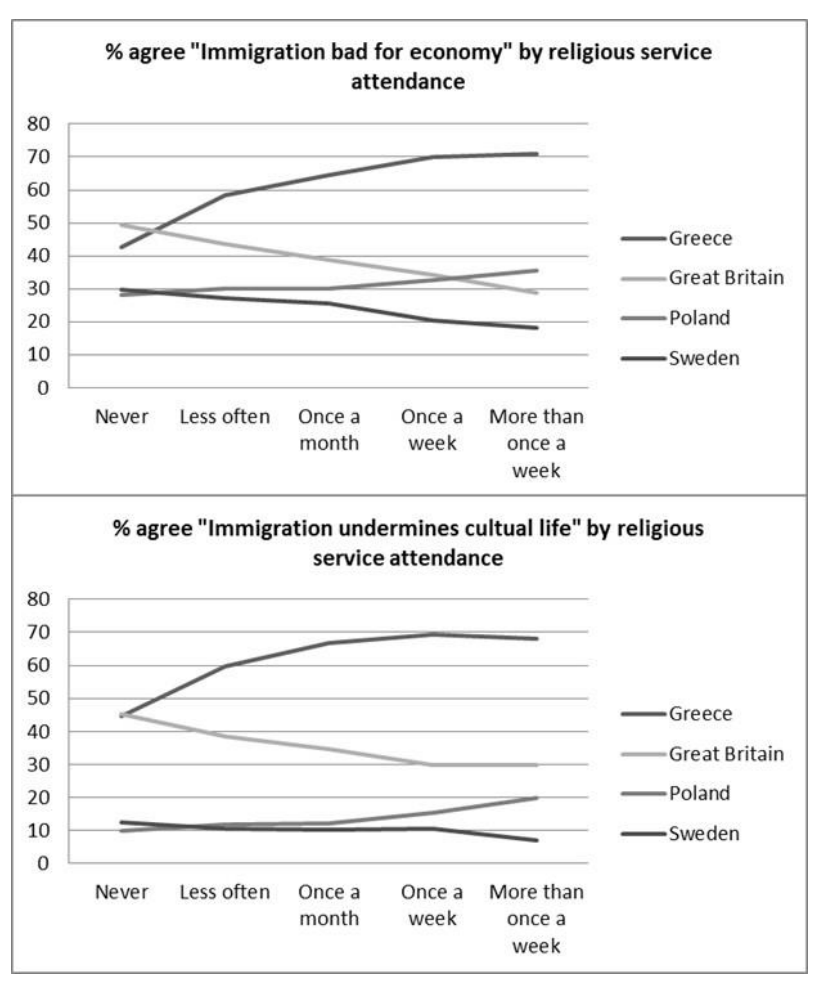

ESS 2002-2014 
Figure 2: Predicted immigration concerns by percentage same religion

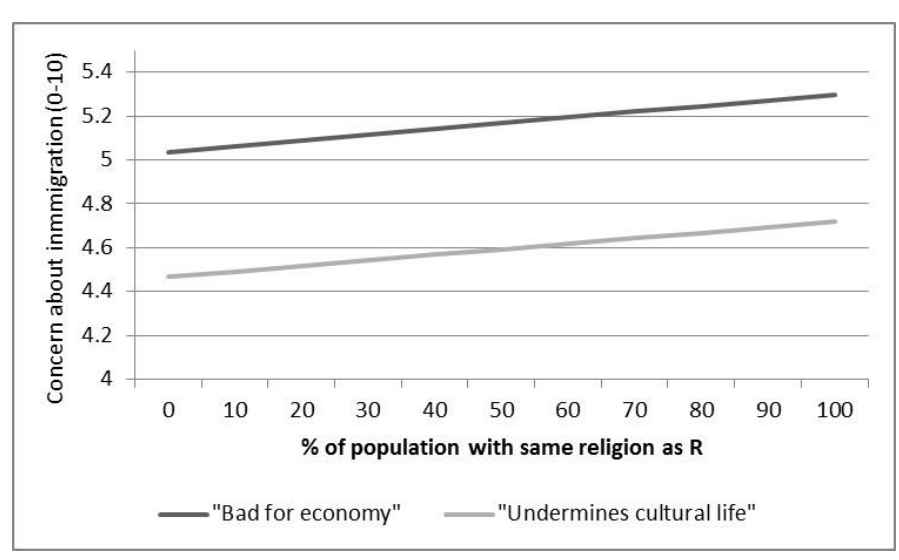

ESS 2002-2014 
Figure 3: Predicted economic concerns about immigration by religious service attendance

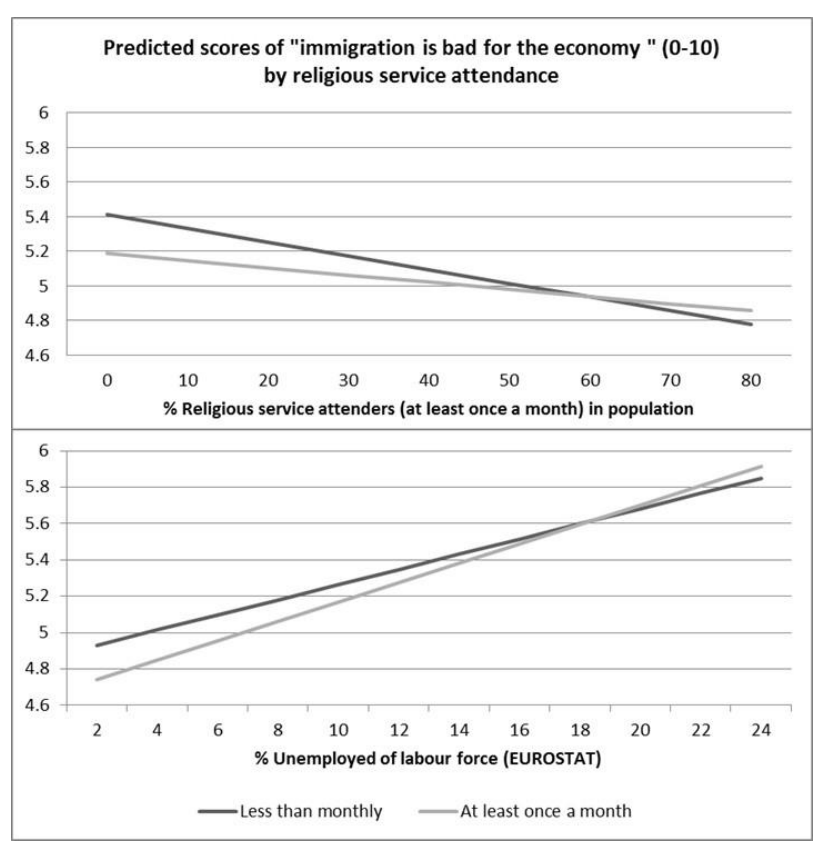

ESS 2002-2014 